\title{
National Medication Errors Reporting System at Ministry of Health in Saudi Arabia
}

Yousef Ahmed Alomi*, (DD The Former General Manager of General Administration of Pharmaceutical Care Former Head, National Clinical Pharmacy and Pharmacy Practice Former Head, Pharmacy R and D Administration Ministry of Health, Riyadh, SAUDI ARABIA

Saeed Jamaan Alghamdi, General Administration of Pharmaceutical Care, Ministry of Health, Riyadh, SAUDI ARABIA. Radi Abdullah Alattyh, General Administration of Pharmaceutical Care, Ministry of Health, Riyadh, SAUDI ARABIA.

\section{Correspondence:}

Dr. Yousef Ahmed Alomi,

The Past General Manager of General Administration of Pharmaceutical Care, The

Past Head, National Clinical Pharmacy and Pharmacy Practice, The Past Head, Pharmacy $R$ and $D$ Administration, Ministry of Health, Riyadh, SAUDI ARABIA.

Phone no: +966504417712

E-mail: yalomi@gmail.com

Received: 14-10-2018;

Accepted: 19-11-2018

Copyright: $\odot$ the author(s),publisher and licensee Pharmacology, Toxicology and Biomedical Reports. This is an open-access article distributed under the terms of the Creative Commons Attribution NonCommercial License, which permits unrestricted non-commercial use, distribution, and reproduction in any medium, provided the original work is properly cited.

This is an open access article distributed under the terms of the Creative Commons Attribution-NonCommercial-ShareAlike 4.0 License

Access this article online

\begin{tabular}{|l|l|}
\hline & www.ptbreports.org \\
& DOI: \\
\hline & \\
&
\end{tabular}

\begin{abstract}
Objective: To demonstrate the medications errors as part of the pharmaceutical care plan at the Ministry of Health of Health foundations in the Kingdom of Saudi Arabia. Method: It is a retrospective analysis of medications error documentation system at the Ministry of Health of Health institutions. The Pharmacy strategic plan 2012-2020 used in the study. The analysis used the modified pharmacy business model system and Project Management Procedure. Results: The medications error documentation system founded with a defined vision, mission and goals. The system had several resources including human or economic and other described in the review. The continuation of the system assured by risk management model description. Also, the monitoring and controlling of the system as illustrated. The convention to operation project though closing project stage demonstrated in the Analysis. Conclusion: The Medications errors documentation system established within the healthcare system and pharmacy regulations. The medications error documentation system is regularly improving accordingly at all Ministry of Health institutions in the Kingdom of Saudi Arabia.

Key words: Clinical outcomes, Pharmacist, Interventions, Critical care services, Private hopsital, Riyadh, Saudi Arabia.
\end{abstract}

\section{INTRODUCTION}

Medication errors are still a major problem in the public health sector in the Kingdom of Saudi Arabia (KSA), Gulf countries and rest of the world. ${ }^{1,2}$ It causes a huge economic burden on the healthcare system. Several associations of pharmacy have published information regarding preventive measures of medication errors. The American Society of Health-System Pharmacists (ASHP) and Institution of Same Medication Practice (ISMP) have published on the regulations and recommendations to prevent the occurrence of medication errors and enhance medication safety. ${ }^{3-6}$ Moreover, the local and international accreditation of healthcare institutions are included as part of their regulations. ${ }^{7,8}$ The pharmacist has a significant role in preventing medication errors and prevent additional cost on the healthcare system. ${ }^{9-12}$ Several studies conducted in the KSA have described the pattern of medication errors, knowledge of medications and the cost of medication errors. ${ }^{2,13-16}$ However, documentation of medication errors at $\mathrm{MOH}$ institutions in Saudi Arabia have not yet been reported. Therefore, in this study, we aimed to explore the national medication errors reporting system by utilizing project management tools at the $\mathrm{MOH}$ institutions in Saudi Arabia.

\section{Method of development of the project}

The medication safety task force committee consisted of expert people from the pharmacies of the $\mathrm{MOH}$ hospitals who set up a national medication errors documentation system for pharmacies of the hospitals, PHCs and dental centers. The first author of this article headed the medication safe- ty committee; he conducted regular meetings. The committee unitized and drove the pharmacy medication errors documentation system of the GAPC and some developing non-MOH hospitals. In addition, the medication errors written by utilizing the international business model, pharmacy guidelines, project management institution guidelines of a new project. ${ }^{17-20}$ The draft was sent to several reviewers of the RAPC. The selection was corrected and updated accordingly. Then, the second draft was submitted to the reviewers again for their final comments and approval. This took around 4 months to complete the task. The GAPC at the MOH sent the final document to all the hospitals for implementation. The medication errors documentation system consisted of several parts including the initial phase, the planning phase, the execution phase and the monitoring and controlling phase.

\section{Initial phase}

\section{Assessment needs}

Medication error is a common problem across many countries around the world. They might cause permanent harm or death of the patient. Several societies of healthcare system have developed guidelines and regulations to prevent such errors. To prevent the occurrence of medication errors, we need to document them so that they are avoided in future. The following information can be documented: the types of medication errors, reasons of errors, factors assisting in preventing medication errors and procedures of medication errors. 


\section{SWOT analysis}

We performed Strengths, Weaknesses, Opportunities and Threats (SWOT) analysis in this study. The strengths of this project are the method to know the occurrence of medication errors, the tool to prevent medication errors in the future and the method to calculate the cost of medication errors. The weaknesses of this project was the increase in the workload of pharmacy staff and some employees were used as part of the pharmacy performance. The opportunities in this project were the medication error system fit with local and national accreditation standards, it is part of medications safety regulations. The threats to this project are changing of pharmacy administration and healthcare insurance not covered under medication errors.

\section{Market Analysis}

Documentation system of medication errors at $\mathrm{MOH}$ was established in early 2000s. The first version was prepared during 2012-2015. ${ }^{21}$ Several institutions have documented medication errors, including non- $\mathrm{MOH}$ governmental hospitals. Some hospitals have an electronic format of documenting medication errors. The format of documentation is unified with all MOH hospitals and PHCs as part of medications safety program. The electronic format was designed through the Survey Monkey system.

\section{Planning phase}

\section{Scope of the project}

The documentation system of medication errors consists of several parts including the demographic information of patients, type of medication errors, domain of healthcare providers who committed the medication errors, the potential severity of medication errors, the causes of medication errors, the type of medications caused of the errors and solutions to prevent medication errors in the future.

\section{Vision, Missions and Goals}

The vision of this project is to have the best documentation system of medication errors and prevent drug related problems and improve patients clinical and economic at $\mathrm{MOH}$ in the KSA. The mission of this project is to provide best system of medication errors documentation to all the healthcare institutions at $\mathrm{MOH}$ in the KSA. The primary objectives or goals of this project are to provide best system of medication errors, to know the occurrence of medication errors and to prevent them from happening in the future.

\section{Project description}

The National Coordinating Council for Medication Error Reporting and Prevention (NCC MERP) defines medication error as the following: "any preventable event that may cause or lead to inappropriate medication use or patient harm while the medication is in the control of the health care professional, patient or consumer. Such events may be related to professional practice, health care products, procedures and systems, including prescribing; order communication; product labeling, packaging and nomenclature; compounding; dispensing; distribution; administration; education; monitoring; and use". ${ }^{22}$

\section{All the pharmacists and healthcare providers should follow this policy}

- If any caregiver, who is observing or is involved in, discovers medication error, then he/she should attend to the "victim," (i.e. patient), visitor or hospital employee and call for help as needed.

- The caregiver should notify his/her supervisor or department director/head as soon as possible after the occurrence or discovery of the medication error and if the occurrence is severe, he/she should take immediate action.
- The attending physician must be notified immediately to take action.

- The immediate supervisor or employer must be notified to assess the outcome and to take action.

- The patient should be monitored for unwanted side effects.

\section{Documenting the Medication Error}

- The individual discovery of the error must follow documentation of the medication error using the Medication Error Reporting Form (Appendix 1). If he/she does not document, then his/her immediate supervisor should ask him/her to document it.

- The following information in the Medication Error Report Form. ${ }^{6,23,24}$ Must be documented by the individual who discovered the error:

$\begin{array}{ll}\text { - } & \text { Patient's information } \\ \text { - } & \text { Time error occurred } \\ \text { - } & \text { Location (Ward/Unit) } \\ \text { - } & \text { Date/time error reported } \\ \text { - } & \text { Date error discovered } \\ \text { - } & \text { Time error discovered } \\ \text { - } & \text { Error committed by } \\ \text { - } & \text { Dosage form } \\ \text { - } & \text { Route of administration } \\ \text { - } & \text { Package container } \\ \text { - } & \text { Error criteria } \\ \text { - } & \text { Stage(s) involved } \\ \text { - } \quad \text { Brief description of error }\end{array}$

The following information in the Medication Error Report Form must be documented by the immediate supervisor or the employer:

- Outcome of the error

- Cost avoidance impact

- Cause of error/contribution factor

- Immediate action taken

- Immediate supervisor or employer should sign the form and forward it to the pharmacy department.

- The following information should be documented by the immediate supervisor or the employer in case of error reaching the patient who required physician intervention.

- Physician follow-up

- The completed Medication Error Report Form should be delivered to the Medication Safety Officer (MSO) in the Pharmacy Department.

- The following information in the Medication Error Report Form must be documented by the MSO or must be documented by the pharmacist or pharmacy technician and then the form should be sent to the MSO at the Pharmacy Department:

- MSO at the Pharmacy Department should document his/her suggestions to prevent recurrence of error based on his/her assessment of the action taken, document it and sign the Medication Error Form.

- The MSO is responsible to send the completed form (and enter the data in the electronic form available on the $\mathrm{MOH}$ website) to the GAPC, National Drug Information Center, Medication Safety Department via fax or email; if the MSO needs to contact the authorized pharmacist, then he/she should contact through telephone no.

- The MSO is responsible to keep all the original completed Medication Error Report Form in a confidential manner. The MSO must not respond to any request from any employee asking for photocopying any Medication Error Report Form to prevent its use 
against any healthcare provider for disciplinary action.

- The MSO is responsible to aggregate the data of all the medication errors reported and formulate a Monthly Medication Errors Summary Report.

- The Director of Pharmacy or designee should review all the Monthly Medication Errors Summary Report.

- The MSO is responsible to submit the Monthly Medication Errors Summary Report to:

- Quality Department

- PTC

- Patient Safety Committee

- Medication Safety Committee

- Note: In addition, the MSO is responsible to submit the report of any independent cases (considered as sentinel event) to them.

- An investigation of the medication errors, its causes and contributing factors should be performed and documented by the MSO in coordination with the affected department(s)/assigned team or perform RCA investigation if the case is considered as a sentinel event.

- Necessary action(s) should be taken with the follow-up as necessary to decrease reoccurrence and to prevent the occurrence of medication errors.

\section{Plan cost management}

The project requires financial cost including the cost for education and training of the staff, outsourcing of electronic database for instant Survey Monkey system, economic factors encouraging the pharmacy staff to facilitate the documentation of medication errors.

\section{Execution phase}

\section{Management team}

The medications safety committee, management team, was responsible for the follow-up of the medication errors reporting and documentation. The central committee designed by General Administration of Pharmaceutical Care (GAPC) at $\mathrm{MOH}$, the committee consisted of representatives from each region specialized in medications safety. Another regional committee established for each region consisted of representatives from each hospital and group primary care center (PHC). Each hospital or group of PHC established local medications safety committee. The local committee consisted of medications safety pharmacist, physician, nurses, quality management, risk management and any invited member. All committees should have a monthly meeting to discuss the medication errors reporting and documentation, medication errors analysis and medication errors prevention. ${ }^{21}$

\section{Education and training}

The project requires that on regular basis, there is educational course about medication errors documentation system through GAPC at $\mathrm{MOH}$ and Regional Pharmaceutical Care Administration (RAPC) for pharmacy administration staff and pharmacy hospital and PHC staff.

\section{Risk Management}

The following are the six types of risk management: budget risks, scope risks, personal risks, schedule risk, technical risks and quality risks. This project might be exposed to budget or personal risks and quality risks. The project might be exposed to budget risk related to no availability of funds for education and training for the personnel involved in the project and if there is not enough budget to covert the medication errors manual documentation to electronic documentation system. The project might be exposed to personal risks such as human resources of pharmacy not available and shortage of staff with high workload of documentation of medication errors. In addition, the pharmacy staff might not have received education or training about the project. The project might be exposed to quality risks such as nonqualified pharmacist being available and training in the quality pharmacy tools. The project might be exposed to other technical risks such as no available electronic system of medication errors documentation.

\section{Monitoring and Controlling Phase}

\section{Project Quality Management}

The process of quantity management during project management professional is one the essential tool to follow-up the implementation of the project and measure the impact of the project. Several quality tools were used in this study, for instance, the adherence of the medication errors documentation according to the international and national standards, the clinical outcome and cost avoidance impact of the medication errors documentation. In addition, the pharmacist satisfaction of the medication errors documentation system at $\mathrm{MOH}$ institution in KSA. ${ }^{25,26}$

\section{Closing of the project}

The documentation system of medication errors at $\mathrm{MOH}$ institutions is an essential tool to prevent adverse drug reactions in the KSA. The system should continue with the involvement of the corporate committee of medication safety and other related committees. An annual report on medication safety should be prepared. Education and training courses for healthcare providers should be conducted regularly. Further expanded of the medication error system with cost avoidance of prevention medication safety in the future. Annual celebration with the involving members of the project is recommended.

\section{ACKNOWLEDGEMENT}

None.

\section{CONFLICT OF INTEREST}

The authors declare no conflict of interest.

\section{ABBREVIATIONS}

MOH: Ministry of Health; KSA: Kingdom of Saudi Arabia; ASHP: American Society of Health-System Pharmacists; ISMP: Institution of Same Medication Practice; RCA: Root Cause Analysis; SWOT: Strengths, Weaknesses, Opportunities and Threats; PTC: Pharmacy and Therapeutic Committee; RAPC: Regional Administration of Pharmaceutical Care; GAPC: General Administration of Pharmaceutical Care; MSO: Medication Safety Officer; NCC MERP: National Coordinating Council for Medication Error Reporting and Prevention.

\section{ORCID ID}

Yousef Ahmed Alomi (iD https://orcid.org/0000-0003-1381-628X

\section{REFERENCES}

1. Alsulami Z, Conroy S, Choonara I. Medication errors in the Middle East countries: A systematic review of the literature. Eur J Clin Pharmacol. 2013;69(4):9951008

2. Khoja T, Neyaz Y, Qureshi NA, Magzoub MA, Haycox A, Walley T. Medication errors in primary care in Riyadh city, Saudi Arabia. 2011

3. Alex JA, Ronna BH, Coleen KEI. ISMP Medication Safety Self-Assessment ${ }^{\circledR}$ for Community/Ambulatory Pharmacy. 2017.

4. Jean C, Wiliam D, Michael E, Michael G, Russel JWM. ISMP Medication Safety Self-Assessment for Antithrombotic Therapy. 2017

5. Cohen MR, et al. ISMP Medication Safety Self-Assessment for High-Alert Medications. 2017.

6. American Society of Hospital Pharmacists. ASHP guidelines on preventing medication errors in hospitals. Am J Hosp Pharm. 2018;75:1493-517.

7. Medication Management (MM). In: National Hospital Standards. $2^{\text {nd }}$ Edition. Saudi Central Board for Accreditation of Healthcare Institutions; 2015;194-211.

8. The Joint Commission. Comprehensive Accreditation Manuals. Joint Commission Resources. 2016. 
9. Alomi YA, Alanazi AA, Alsallouk SA, Almadni O, Almaznai MM, Mossa K, et al. Pharmacist intervention of prevention medication errors at pediatrics, obstetrics and gynecology hospital, East Province, Saudi Arabia. In: Value in Health. 2017;20(5):A39.

10. Alomi YA, Al-Shubbar NA, Lubad NA. Inpatient Medication Errors and Pharmacist Intervention at Ministry of Health Public Hospital in Riyadh, Saudi Arabia. Value Heal. 2017;20(9):A690

11. AlomiYA, Alanazi AA, Alsallouk SA, Almaznai MM, Abu-Alnaja NI, Alduhilan M, et al. Cost-Efficiency Of Medication Safety Program At Pediatrics, Obstetrics and Gynecology Hospital, East Province, Saudi Arabia. Value Heal. 2016;19(7):A464.

12. Alomi YA, Al-Shubbar NA, Lubad NA. Economics outcomes of medication safety program at public hospital in Riyadh, Saudi Arabia. In: Value in Health. 2017:20(5):A32-A32.

13. Al-Dhawailie AA. Inpatient prescribing errors and pharmacist intervention at a teaching hospital in Saudi Arabia. Saudi Pharm J. 2011;19(3):193-6.

14. Al-Arifi MN. Community pharmacists' attitudes toward dispensing errors at community pharmacy setting in Central Saudi Arabia. Saudi Pharm J. 2014;22(3):195-202.

15. Alomi YA, Al-shaibani AS, Alfaisal G, Alasmi NM. Cost Analysis of Drug-related Problems in Saudi Arabia: Patients' and Healthcare Providers' Perspective. J Pharm Pract Community Med. 2018;4(2):107-12.

16. Dibbi HM, Al-Abrashy HF, Hussain WA, Fatani MI, Karima TM. Causes and outcome of medication errors in hospitalized patients. Saudi Med J. 2006;27(10):1489-92.

17. McDonough R. Writing a Business Plan for a New Pharmacy Service. The Dy- namics of Pharmaceutical Care: Enriching Patients' Health. 2010;23.

18. Harris IM, Baker E, Berry TM, Halloran MA, Lindauer K, Ragucci KR, et al. Developing a Business-Practice Model for Pharmacy Services in Ambulatory Settings. Pharmacotherapy. 2008;28(2):7e-34e.

19. Sachdev G. Sustainable business models: Systematic approach toward successful ambulatory care pharmacy practice. Am J Heal Pharm. 2014;71(16):1366-74.

20. PMBOK Guide. A Guide to the Project Management Body of Knowledge. $6^{\text {th }}$ Edit. Project Management Institute, Inc. 2017.

21. Alomi YA. National Medication Safety Program at Ministry of Health in Saudi Arabia. J Pharmacovigil. 2015;3(5):e145.

22. The National Coordinating Council for Medication Error Reporting and Prevention (NCC MERP). Consumer Information for Safe Medication Use | NCC MERP [Internet]. [cited 2019 Jan 23]. Available from: https://www.nccmerp.org/consumer-information

23. Ling JM, Mike LA, Rubin J, Abraham P, Howe A, Patka J, et al. Documentation of pharmacist interventions in the emergency department. Am J Heal Pharm. 2005;62(17):1793-7.

24. Mutnick AH, Sterba KJ, Peroutka JA, Sloan NE, Beltz EA, Sorenson MK. Cost savings and avoidance from clinical interventions. Am J Heal-Sys Pharm. 1997;54(4):392-6.

25. Alomi YA, Alghamdi SJ, Alattyh RA. Strategic Plan of General Administration of Pharmaceutical Care at Ministry of Health in Saudi Arabia 2012 - 2022. JPharm Pharm Scien. 2015;1(13):1-8.

26. Alomi Y. National Pharmacy Administration Programs. BAOJ Pharm Sci. 2015;1(2):1-2. 


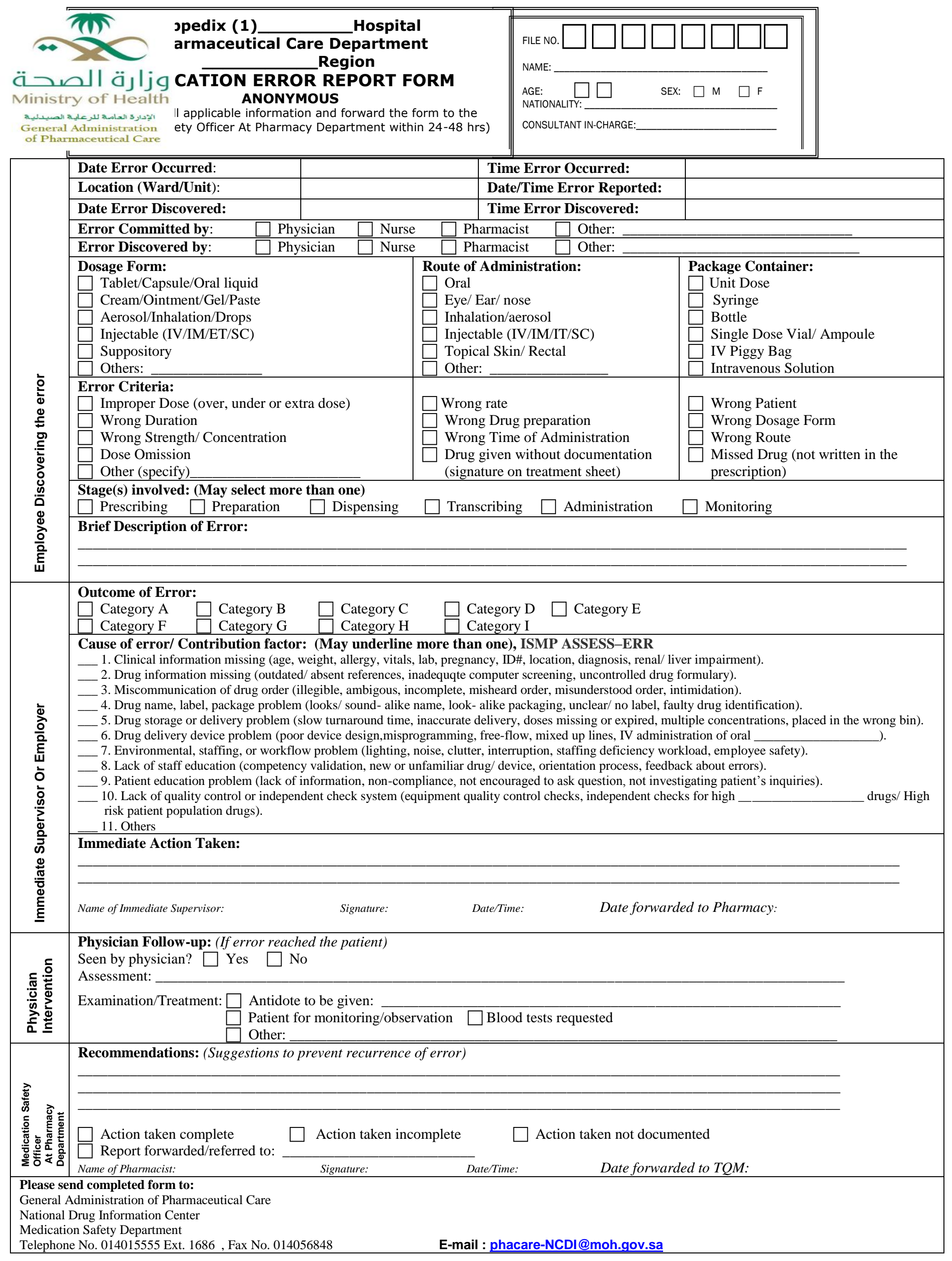




\section{DEFINITIONS:}

1. Medication error is any preventable event that may cause or lead to inappropriate medication use or to patient harm while the medication is in the control of the healthcare professional, patient, or consumer. Such events may be related to professional practice; healthcare products, procedures, and systems, including prescribing, order communication; product labelling, packaging, and nomenclature; compounding; dispensing; distribution; administration; education; monitoring; or use. A broader definition is any error that occurs in the medication-use process. ${ }^{1}$

2. Risk: Hazardous conditions that could lead to an error, such as products with look-alike packaging or names, ambiguous product labels, error-prone medication delivery devices (e.g., pumps), error-prone functions in computerized prescriber order entry system, unsafe environmental conditions (e.g., noise, poor lighting, and clutter), staffing shortages that result in excessive workload and fatigue, intimidating behaviors, out-of-date drug references, use of error-prone abbreviations, and medication-related device hazards. ${ }^{2}$

3. Near Miss: A medication error that was detected and corrected before it reached the patient, and according to ISMP definition the near miss, is an event, situation, or error that took place but was captured before reaching the patient. For example, penicillin was ordered for a patient allergic to the drug; however, the pharmacist was alerted to the allergy during the computer order entry, the prescriber was called, and the penicillin was not dispensed or administered to the patient, or the wrong drug was dispensed by pharmacy, and a nurse caught the error before it was administered to the patient. ${ }^{3}$

4. The outcome of errors categories based on NCC MERP, and the definition of near miss from ISMP; Category A is Risk and Category B is Near miss. ${ }^{4}$

5. According to definition of sentinel event from $\mathrm{MOH}$ policy and procedure. Category $\mathbf{G}, \mathbf{H}$, and $\mathbf{I}$ is Sentinel Event and should be reported within 24 hours Total Quality Department at Hospital or Primary Healthcare Center ${ }^{5}$.

6. For all discovered medication errors, Medication Error Report Form should be completed and forwarded after all necessary information has been gathered to pharmacy department within 24-48 hours.

\section{References}

1. Smetzer JL and Cohen MR., Definitions. Ch: Medication Error Reporting Systems, Editing: Cohen MR Medication Errors, $2^{\text {nd }}$ Edition, Pharmacy Library, accessed 21/8/2012

2. Smetzer JL and Cohen MR. Reportable Events, Conditions, and Priorities, Ch: Medication Error Reporting Systems, Editing: Cohen MR Medication Errors, $2^{\text {nd }}$ Edition, Pharmacy Library, accessed 21/8/2012

3. ISMP survey helps define near miss and close call. ISMP Medication Safety Alert Acute Care. September 24, 2009

4. Smetzer JL and Cohen MR. Categorizing Reports, Ch: Medication Error Reporting Systems, Editing Cohen MR Medication Errors, $2^{\text {nd }}$ Edition, Pharmacy Library, accessed 21/8/2012

5. Sentinel Event Policy and Procedures, Ministery of Health. 